\title{
Comparable outcome for autografts and allografts in primary medial patellofemoral ligament reconstruction for patellofemoral instability: systematic review and meta-analysis
}

\author{
Filippo Migliorini ${ }^{1}$ (D) Andromahi Trivellas ${ }^{2} \cdot$ Jörg Eschweiler $^{1} \cdot$ Matthias Knobe $^{3} \cdot$ Markus Tingart $^{1}$. \\ Nicola Maffulli ${ }^{4,5,6}$
}

Received: 10 January 2021 / Accepted: 6 April 2021 / Published online: 16 April 2021

(c) The Author(s) 2021

\begin{abstract}
Purpose This study updates the current evidence on the role of allografts versus autografts for medial patellofemoral ligament (MPFL) reconstruction in patients with patellofemoral instability.

Methods The study was performed according to the PRISMA guidelines. In March 2021, a literature search in the main online databases was performed. Studies reporting quantitative data concerning primary MPFL reconstruction using an allograft were considered for inclusion. The Coleman Methodology Score was used to assess the methodological quality of the selected articles.

Results Data from 12 studies (474 procedures) were retrieved. The mean follow-up was 42.2 (15-78.5) months. The mean age was $21.1 \pm 6.2$ years. $64.9 \%$ (285 of 439$)$ of patients were female. At the last follow-up, the Tegner $(p<0.0001)$, Kujala $(p=0.002)$ and the Lysholm $(p<0.0001)$ scores were minimally greater in the autografts. The similarity was found in the rate of persistent instability sensation and revision. The allograft group evidenced a lower rate of re-dislocations $(p=0.003)$. Conclusion Allografts may represent a feasible alternative to traditional autograft for MPFL reconstruction in selected patients with patellofemoral instability. Allograft tendons yielded similar PROMs, rates of persistent instability, and revision. Allograft reconstructions tended to have modestly lower re-dislocation rates.
\end{abstract}

Level of evidence IV.

Keywords Patellofemoral instability $\cdot$ MPFL reconstruction $\cdot$ Allograft

Filippo Migliorini

migliorini.md@gmail.com

1 Department of Orthopaedics, University Clinic Aachen, RWTH Aachen University Clinic, Pauwelsstraße 30, 52074 Aachen, Germany

2 Department of Orthopaedics, David Geffen School of Medicine at UCLA, Los Angeles, CA, USA

3 Department of Orthopedics and Trauma Surgery, Lucerne Cantonal Hospital, Lucerne, Switzerland

4 Department of Medicine, Surgery and Dentistry, University of Salerno, Via S. Allende, 84081 Baronissi, SA, Italy

5 School of Pharmacy and Bioengineering, Keele University School of Medicine, Thornburrow Drive, Stoke on Trent, England, UK

6 Barts and the London School of Medicine and Dentistry, Centre for Sports and Exercise Medicine, Mile End Hospital, Queen Mary University of London, 275 Bancroft Road, London E1 4DG, England, UK

\section{Introduction}

Patellofemoral instability is common, especially in young and adolescent patients [40]. The condition is multifactorial and can be associated with valgus deformity of the knee, mal-alignment syndromes, patella alta, femoral anteversion, patellar dysplasia, trochlear dysplasia, and other less common pathoanatomical conditions $[4,47,50]$. Independent from the specific cause of the instability, following patellar dislocations the medial patellofemoral ligament (MPFL) is most often damaged [10,31]. This ligament is an important dynamic restraint to patellar lateralization during the first degrees of knee flexion, and therefore its reconstruction is often indicated when it is damaged [16, 38]. Reconstruction of the MPFL, in combination with additional stabilization procedures when indicated, yields predictable improvements in patellar stability and patient satisfaction [3, 39]. Importantly, the net forces on the patella result in a lateral 
vector pull on the patella in patients with recurrent patellofemoral instability [41]. The rate of re-dislocations after isolated MPFL reconstruction is $2.7-3.8 \%$ [5, 37, 52]. Graft choice is crucial to prevent surgical failures. Semitendinosus and gracilis autografts are the most common autografts used for MPFL reconstruction [28, 41]. Alternatively, synthetic grafts, allografts, or autografts such as quadriceps, patellar, adductor magnus tendons and other less commonly used grafts can be harvested for reconstruction $[3,30,33$, 42]. The role of allografts for MPFL reconstruction is still unclear. Whether allografts have comparable or even better outcomes than autografts is controversial [36, 45, 59]. Several recent clinical studies have not yet been previously considered for analysis elsewhere [13, 15, 18, 20, 27, 32, 34, 35]. Therefore, a systematic review and meta-analysis were conducted to update the current evidence and systematically compares allografts versus autografts for MPFL reconstruction in patients with patellofemoral instability. The focus of the present investigation was on patient-reported outcome measures (PROMs) and complications. A hypothesis was made that allografts and autografts achieve similar outcome following reconstruction of the MPFL.

\section{Materials and methods}

\section{Search strategy}

The present study was conducted according to the Preferred Reporting Items for Systematic Reviews and Meta-Analyses: the PRISMA statement [44]. The literature search was developed according to the PICO framework:

- P (Population): patellofemoral instability;

- I (Intervention): MPFL reconstruction;

- C (Comparison): autograft versus allograft;

- (Outcomes): PROMs and complications.

\section{Literature search}

Two independent reviewers $(* * ; * *)$ performed the literature search in March 2021. The main online databases were accessed: MEDLINE, EMBASE, Google Scholar, Scopus, Cochrane Library. The following keywords were used in combination: knee, patella, kneecap, patellofemoral, instability, dislocation, recurrent, medial patellofemoral ligament, MPFL, reconstruction, graft, allograft, surgery, treatment, therapy, Kujala, Tegner, Lysholm, persistent, sensation, revision, re-operation, failure, re-dislocation, recurrence. The resulting titles were screened for inclusion. If the title matched the topic, the abstract was accessed. If the abstract matched the topic, the full-text article was accessed. The bibliographies of the full-text articles were screened to uncover papers not retrieved in the search process. Disagreements between the reviewers were discussed and resolved by a third author $(* *)$.

\section{Eligibility criteria}

All the studies reporting data concerning primary MPFL reconstruction via allograft were considered for inclusion. Given the authors' language capabilities, articles in English, Italian, German, Spanish, and French were reviewed. Level of evidences I to V, according to the Oxford Centre of Evidenced-Based Medicine [21], were eligible. Articles regarding revision settings were excluded. Articles reporting on combined and isolated procedures were included. Both recurrent and acute dislocations were considered for inclusion. Cadaveric, animal, and biomechanical studies were excluded. Revisions, registries, letters, expert opinions, commentaries, and technique guides were excluded. Only articles reporting quantitative data on PROMs and complications were included.

\section{Data extraction}

Two authors $(* * ; * *)$ independently performed data extraction. Study generalities and patient baseline data (number of patients and procedures, mean age and gender), duration of follow-up, type of instability (recurrent, acute), and intervention (isolated, combined) were collected. The following patient-reported outcome measures (PROMs) were collected: Kujala Anterior Knee Pain Scale [26], Lysholm Knee Scoring Scale [58], Tegner Activity Scale [8]. Data concerning the following complications were retrieved: the persistent sensation of instability, revision and re-dislocation. Sensation of persistent instability was defined as recurrence and/or subjective sensation of subluxation or instability [46].

\section{Methodological quality assessment}

For the methodological quality assessment, the Coleman Methodology Score (CMS) was calculated [11]. This score is divided into "part A" (analyzing the study size, followup, surgical approach, type of analysis, description of diagnosis, surgical technique, and postoperative rehabilitation) and "part B" (examining the outcomes criteria and related assessing procedures and the description of the subject selection process). The CMS scored the quality of the study from 0 (poor) to 100 (excellent).

\section{Statistical analysis}

The statistical analysis was performed by the main author $(* *)$. The Shapiro-Wilk test was performed to investigate data distribution. For normal data, the mean and standard 
deviation were calculated. For non-parametric data, median and interquartile range were calculated. Respectively, the Student $t$ and Mann-Whitney $U$ tests were performed, with values of $p<0.05$ considered statistically significant. The odd ratio (OR) effect measure was used to investigate the rate of complications, with values of $\chi^{2}$ test $<0.05$ considered statistically significant. Studies that directly compared allografts versus autografts were included in the meta-analysis. The meta-analyses were performed using the Review Manager Software 5.3 (The Nordic Cochrane Collaboration, Copenhagen) for the meta-analyses. For baseline comparability, the unpaired $t$ test was performed, with values of $p>0.5$ being considered satisfactory. To evaluate the Kujala score, the inverse variance was adopted for continuous variables, with MD effect measure. Re-dislocations were evaluated through a Mantel-Haenszel analysis, with the OR effect measure. Heterogeneity was assessed through the Higgins- $\mathrm{I}^{2}$ test. If $I^{2}$ test $>50 \%$, high heterogeneity was detected. The comparisons were performed with a fixed model effect. In cases of heterogeneity, a random model effect was used. The confidence intervals (CI) were set at $95 \%$ in all comparisons. The overall effect was considered statistically significant if $p<0.05$. The funnel plot of the most commonly reported outcome was performed to assess the risk of publication bias. Egger's linear regression was performed through the STATA MP Software version 16 (StataCorp, College Station, USA) to assess funnel plot asymmetry, with values of $p>0.05$ considered satisfactory.

\section{Results}

\section{Search result}

The initial search resulted in 71 published articles. Of these, 29 were duplicates and, therefore, rejected. Another 21 studies were excluded as they did not match the preferred eligibility criteria: language limitation $(N=1)$, type of study $(N=13)$, cadaveric/biomechanical work $(N=4)$, or other $(N=3)$. An additional nine studies were excluded because of lack of reporting of quantitative data under the outcomes of interests. This left 12 retrospective studies for analysis. The flow-chart of the literature search is shown in Fig. 1.

\section{Methodological quality assessment}

The retrospective nature of the included studies is an important limitation. Moreover, no included study performed a prospective analysis or provided any randomization or blinding methods. The follow-up durations and the number of included procedures were appropriate in most studies. The descriptions of the diagnoses, even if no percentages were reported, were adequate, as were the descriptions of surgical procedures and post-operative rehabilitation protocols. Ultimately, the CMS scored 56.1/100 (37-69). The relatively low score brings witness to the moderate quality of the published studies included in the present investigation. The CMS score related to each study is shown in Table 1.

\section{Risk of publication bias}

The referral points were located into the shapes of acceptability, demonstrating good distribution. According to the Egger's test, no statistically significant asymmetry was found. Concluding, the risk of publication bias was low. The funnel plot is shown in Fig. 2.

\section{Patient demographic}

Data from 474 procedures (439 patients) were retrieved. The mean follow-up was 42.2 (15-78.5) months. The mean age was $21.1 \pm 6.2$ years. $64.9 \%$ (285 of 439 ) of patients were female. Good between-group comparability was found concerning patient age and gender. Study generalities and patient baseline are shown in Tables 1 and 2 .

\section{Outcomes of interest}

At last follow-up, the Tegner scale score was greater in the autografts $(p<0.0001)$, as were the Kujala $(p=0.002)$ and the Lysholm $(p<0.0001)$ scores (Table 3).

Similarity was found in the rate of persistent instability sensation and revision. The allograft group evidenced a lower rate of re-dislocations ( $p=0.003)$ (Table 4).

\section{Meta-analysis of direct comparisons}

Three comparative studies $[27,35,56]$ reported data on the Kujala score, and were included in the meta-analysis (Fig. 3). The Kujala score evidenced no difference between the two cohorts.

Six comparative studies $[9,15,18,27,35,56]$ reported data on re-dislocation rate and were included in the metaanalysis (Fig. 4). The allograft group evidenced a lower rate of re-dislocations $(p=0.002)$.

\section{Discussion}

According to the main findings of the present systematic review and meta-analysis, autografts and allografts may achieve similar results for MPFL reconstruction in selected patients with patellofemoral instability. Although PROMs were greater in the autografts group, they did not go above the minimal clinically important difference (MCID) [1, $8,12,24]$, and the meta-analysis did not evidence any 
Fig. 1 PRISMA flow-chart of the literature search

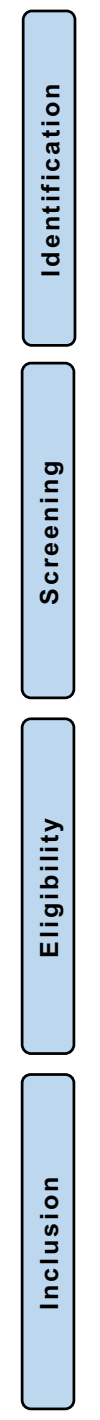

Articles removed because of duplicated $(n=29)$

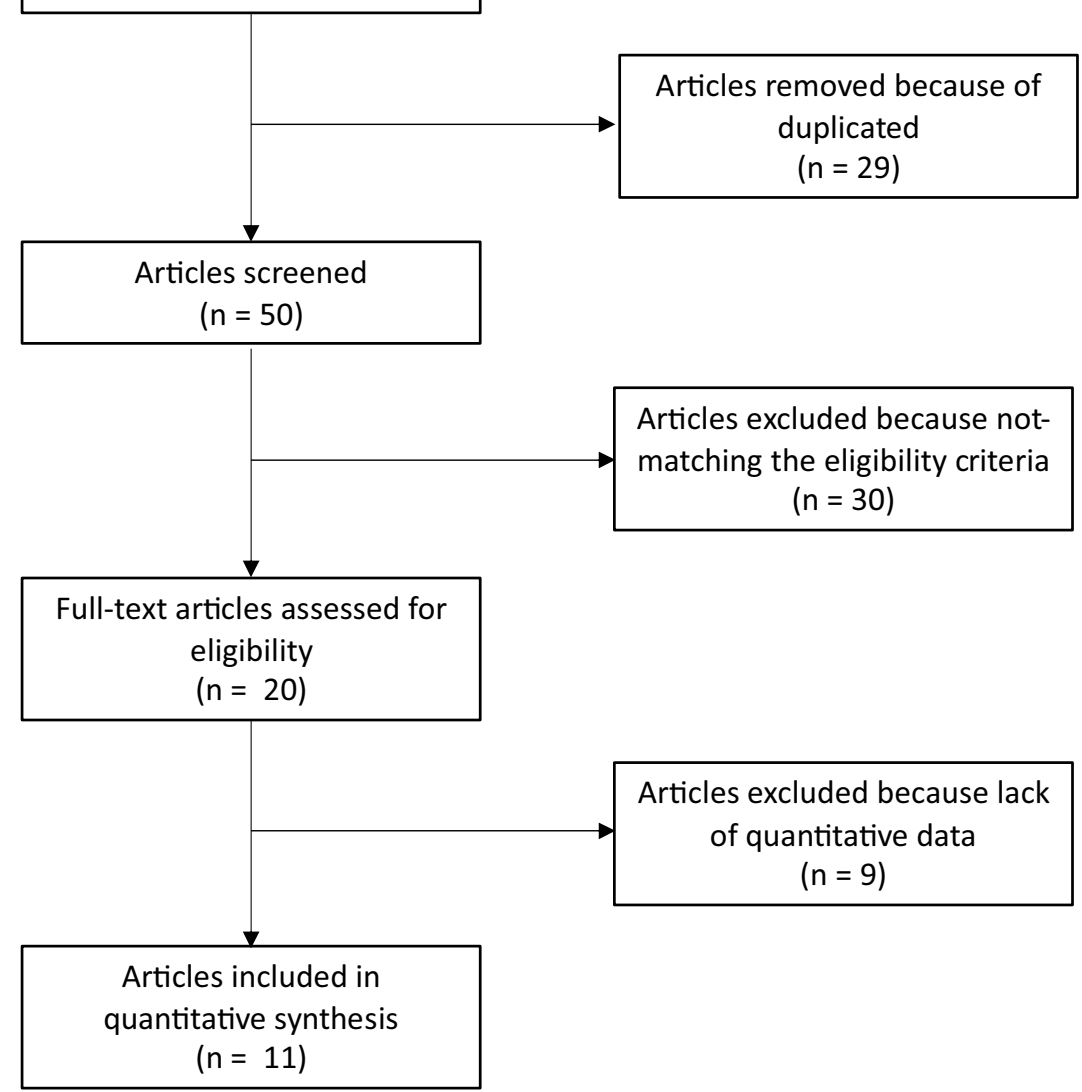

statistically significant difference between the auto- and allografts in terms of rates of persistent instability and revision. Allograft reconstructions tended to have a lower redislocation rate than autografts.

Three previous systematic reviews are available. Nha et al. [45] recently performed a systematic review including only one study [13] involving eight patients for comparison into the allograft group and 21 studies on autografts. McNeilan et al. [36] performed another systematic review in 2018 analyzing two studies $[30,53]$ in the allograft cohort. Given the limited evidence and the poor quality of the included studies, the two studied did not allow any evidenced-based recommendations. Weinberger et al. [59] performed a systematic review including 132 allograft procedures (seven studies), concluding that autografts provided greater Kujala Anterior Knee Pain Scale scores and similar revision-rates compared to the allograft.

This systematic review and meta-analysis included the most recent evidence, increasing the number of studies and the number of outcomes of interest. In our analyses, the PROMs were similar among the two types of grafts. The intra-study variability can explain the low-moderate heterogeneity detected by the $I^{2}$ and $\chi^{2}$ test in the Kujala score. The rates of persistent sensation of instability and revision were comparable between the two types of grafts. The analysis of re-dislocation was characterized by no heterogeneity, detecting an OR modestly in favor of the allograft group. However, only four studies were used for re-dislocation and 3 of the 4 studies have OR which crossed 1, suggesting no difference between the graft choices (Fig. 4). The result of this endpoint was strongly influenced by the studies by Hendawi et al. [18] and Kumar et al. [27]. However, their populations included only patients younger than the overall mean age of the patients in the studies that met our inclusion criteria. Hendawi et al. [18], in a retrospective study, changed from gracilis autograft to gracilis allograft because they were experiencing more failures with that autologous graft. However, instead of considering other autograft choices, such as 
Table 1 Generalities and Coleman Methodology Score (CMS) of the included studies

\begin{tabular}{|c|c|c|c|c|c|c|c|c|c|}
\hline Author, year & Journal & CMS & $\begin{array}{l}\text { Follow- } \\
\text { up } \\
\text { (months) }\end{array}$ & Treatment & Type of graft & Samples $(n)$ & Procedures $(n)$ & Mean age & Female $(\%)$ \\
\hline \multirow[t]{2}{*}{$\begin{array}{l}\text { Calco Rodriguez } \\
\text { et al. (2015) [9] }\end{array}$} & \multirow[t]{2}{*}{$\begin{array}{l}\text { Rev Esp Cir } \\
\text { Ortop Trau- } \\
\text { matol }\end{array}$} & \multirow[t]{2}{*}{49} & \multirow[t]{2}{*}{12} & Allograft & $\begin{array}{l}\text { Semitendino- } \\
\text { sus, Gracillis, } \\
\text { Tibialis anterior } \\
\text { and posterior, } \\
\text { Peroneus, } \\
\text { quadriceps }\end{array}$ & 13 & 13 & 21.0 & 69.2 \\
\hline & & & & Autograft & $\begin{array}{l}\text { Semitendinoso, } \\
\text { Gracilis }\end{array}$ & 15 & 16 & 22.0 & 40.0 \\
\hline $\begin{array}{l}\text { Dragoo et al. } \\
\text { (2017) [13] }\end{array}$ & $\begin{array}{l}\text { Orthop J Sports } \\
\text { Med }\end{array}$ & 41 & 51 & Allograft & $\begin{array}{l}\text { Semitendinosus, } \\
\text { Gracilis }\end{array}$ & 8 & 8 & 36.3 & 87.5 \\
\hline \multirow[t]{2}{*}{$\begin{array}{l}\text { Flanigan et al. } \\
\text { (2020) [15] }\end{array}$} & \multirow{2}{*}{$\begin{array}{l}\text { Knee Surg Sports } \\
\text { Traumatol } \\
\text { Arthrosc }\end{array}$} & \multirow[t]{2}{*}{53} & \multirow[t]{2}{*}{49.2} & Allograft & $\begin{array}{l}\text { Semitendinosus, } \\
\text { Gracilis }\end{array}$ & 37 & 57 & 25.8 & 70.3 \\
\hline & & & & Autograft & $\begin{array}{l}\text { Semitendinosus, } \\
\text { Gracilis }\end{array}$ & 16 & 30 & 23.5 & 68.8 \\
\hline \multirow{2}{*}{$\begin{array}{l}\text { Hendawi et al. } \\
\text { (2019) [18] }\end{array}$} & \multirow[t]{2}{*}{ Ochsner J } & \multirow[t]{2}{*}{37} & \multirow[t]{2}{*}{$>6$} & Allograft & Gracilis & 35 & 35 & 16.0 & 68.6 \\
\hline & & & & Autograft & Gracilis & 21 & 21 & 15.3 & 81.0 \\
\hline $\begin{array}{l}\text { Hohn et al. (2017) } \\
\text { [20] }\end{array}$ & $\begin{array}{l}\text { Clin Orthop Rel } \\
\text { Res }\end{array}$ & 49 & 24 & Allograft & Gracilis & 25 & 25 & 16.0 & 72.0 \\
\hline \multirow{2}{*}{$\begin{array}{l}\text { Kumar et al. } \\
\text { (2018) [27] }\end{array}$} & \multirow{2}{*}{$\begin{array}{l}\text { Orthop J Sports } \\
\text { Med }\end{array}$} & \multirow[t]{2}{*}{61} & 37.2 & Allograft & Hamstring & 36 & 36 & 15.3 & 61.1 \\
\hline & & & 68.4 & Autograft & Gracils & 23 & 23 & 14.9 & 69.6 \\
\hline $\begin{array}{l}\text { Li et al. (2014) } \\
\text { [30] }\end{array}$ & J Orthop Sur Res & 63 & 78.5 & Allograft & Tibialis anterioris & 65 & 65 & 29.4 & 56.9 \\
\hline $\begin{array}{l}\text { Marcheggiani } \\
\text { Muccioli et al. } \\
\text { [32] }\end{array}$ & $\begin{array}{l}\text { Knee Surg Sports } \\
\text { Traumatol } \\
\text { Arthrosc }\end{array}$ & 69 & 60 & Allograft & Fascia lata & 17 & 17 & 21.7 & 35.3 \\
\hline $\begin{array}{l}\text { Matuszewski } \\
\text { et al. (2017) } \\
\text { [34] }\end{array}$ & $\begin{array}{l}\text { Chir Narzadow } \\
\text { Ruchu Ortop } \\
\text { Pol }\end{array}$ & 51 & 15 & Allograft & $\begin{array}{l}\text { Tensor fasciae } \\
\text { latae }\end{array}$ & 15 & 15 & 13.1 & 66.7 \\
\hline \multirow{2}{*}{$\begin{array}{l}\text { Matuszewski } \\
\text { et al. (2018) } \\
\text { [35] }\end{array}$} & \multirow[t]{2}{*}{ Medicine } & \multirow[t]{2}{*}{65} & \multirow[t]{2}{*}{24} & Allograft & $\begin{array}{l}\text { Tensor fasciae } \\
\text { latae }\end{array}$ & 22 & 22 & 15.0 & 54.5 \\
\hline & & & & Autograft & Gracilis & 22 & 22 & 15.0 & 68.2 \\
\hline \multirow{2}{*}{$\begin{array}{l}\text { Slenker et al. } \\
\text { (2013) [53] }\end{array}$} & \multirow[t]{2}{*}{ Phys sportsmed } & \multirow[t]{2}{*}{66} & \multirow[t]{2}{*}{21} & Allograft & Soft tissue & 23 & 23 & 20.6 & 65.7 \\
\hline & & & & Autograft & Hamstring & 12 & 12 & & \\
\hline \multirow{3}{*}{$\begin{array}{l}\text { Steiner et al. } \\
\text { (2006) [56] }\end{array}$} & \multirow[t]{3}{*}{ Am J Sports Med } & \multirow[t]{3}{*}{69} & \multirow[t]{3}{*}{66.5} & Allograft & Patellar & 5 & 5 & 27.0 & 64.7 \\
\hline & & & & Autograft & Adductor & 23 & 23 & & \\
\hline & & & & Autograft & Quadriceps & 6 & 6 & & \\
\hline
\end{tabular}

semitendinosus, they chose to change to gracilis allografts, which incidentally had the same diameter as the gracilis autograft they were originally using [41]. They also admitted that the learning curve may have potentially biased their results. Kumar et al. [27] combined various procedures in addition to the MPFL reconstruction. In their study, seven of the allograft patients had a lateral release versus only two in the autograft patients. Their autograft cohort had six re-dislocation versus 3 in the allograft cohort. It would be difficult to conclude the re-dislocation rate is a consequence of the graft per se, as lateral release had been often used in combination with MPFL reconstruction.

Advantages of allografts are shorter surgical duration and less donor site morbidity. This may also lead to less pain and favour the early phases of rehabilitation, resulting in earlier recovery of muscle function. Potential infections and sterilization processes of allografts should be addressed briefly. Allografts carry a potential risk of disease transmission; however, sterilization processes may affect the quality and mechanical proprieties of the graft. One method of sterilization, using ethylene oxide, does not interfere with the mechanical quality of the graft but has been associated with persistent synovitis $[23,51]$. To avoid this, $\gamma$-ray irradiation has been proposed. However, in vivo comparisons between irradiated and non-irradiated allografts discouraged the use of irradiated ones. Irradiated allografts were associated with a considerably higher failure rate, reducing their strength in a dose-dependent manner $[49,57]$. There is a renewed 
Fig. 2 Funnel plot of the most commonly reported outcome (re-dislocation) ( $S E$ standard error, $O R$ odd ratio)

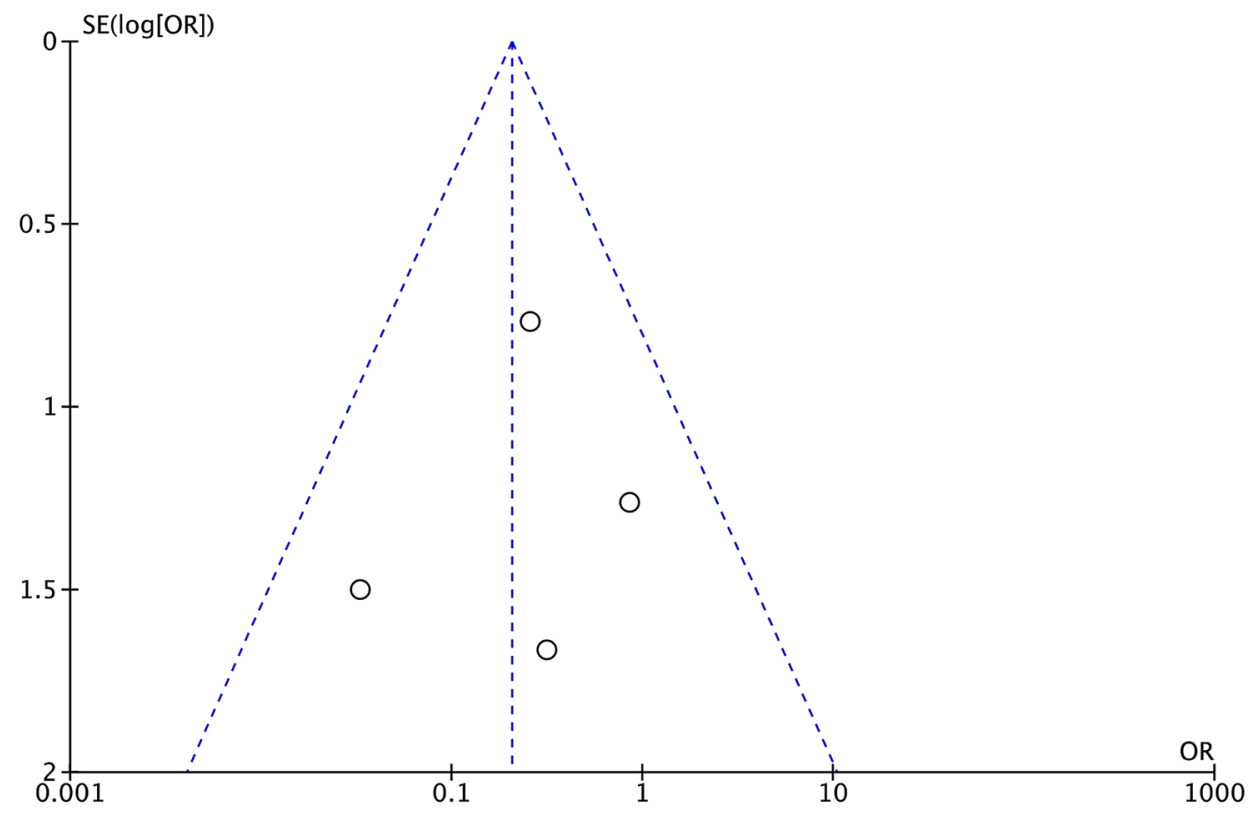

interest in the prevention of infection in ligament reconstruction surgery. It is possible that devices developed for intra-articular ligament reconstruction procedures may well be used in MPFL reconstruction, especially when employing allografts [2]. Surgeons must be aware of the storage processes, sterilization methods, and standards of the tissue bank they use. Furthermore, the issue of cost-effectiveness of the allograft is still controversial. Hendawi et al. [18] concluded that allografts used for MPFL reconstructions were cheaper than autografts. The analysis was based on surgical duration, service costs, and reoperation rates. However, there are limited additional data on this specific issue. The costeffectiveness of allografts versus autografts has been extensively investigated in other orthopaedic procedures such as anterior cruciate ligament (ACL) reconstruction. Allografts are expensive, and this has not been shown to be always offset by a shorter surgical duration $[17,43]$ in ACL procedures. However, even though well documented, the role of allografts in ACL reconstruction has also not been fully agreed upon $[22,25,48,60]$. Nonetheless, comparing the use of an allograft for MPFL reconstruction with the use of allograft for ACL reconstruction may be improper because

\begin{tabular}{llllll}
\hline Endpoint & Allograft & Autograft & $95 \%$ CI & OR & $p$ \\
\hline Re-dislocation & $2.5 \%(8$ of 321$)$ & $9.2 \%(14$ of 153$)$ & 0.1041 to 0.6188 & 0.3 & 0.003 \\
Persistent instability & $29.8 \%(17$ of 57$)$ & $36.7 \%(11$ of 30$)$ & 0.2883 to 1.8691 & 0.7 & n.s \\
Revision & $7.9 \%(3$ of 38$)$ & $6.3 \%(1$ of 16$)$ & 0.1235 to 13.3827 & 1.3 & n.s \\
\hline
\end{tabular}

Data are presented as percentage, number of events and observations, odd ratio (OR), confidence interval (CI), and the $p$ value resulting from the $\chi^{2}$ test

n.s. not significant 


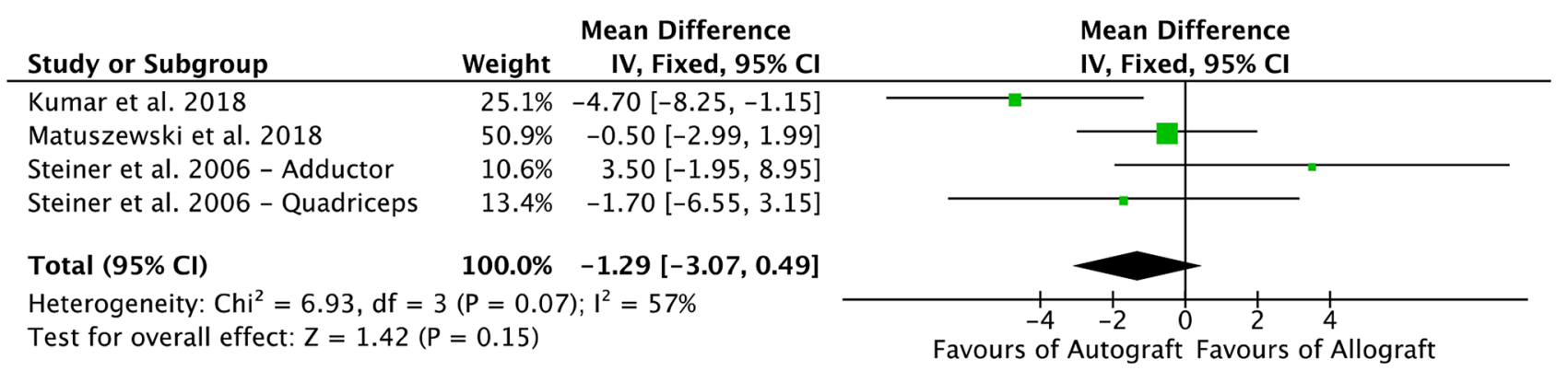

Fig. 3 Forest plot of the outcome: Kujala score (IV inverse variance, $C I$ confidence interval)

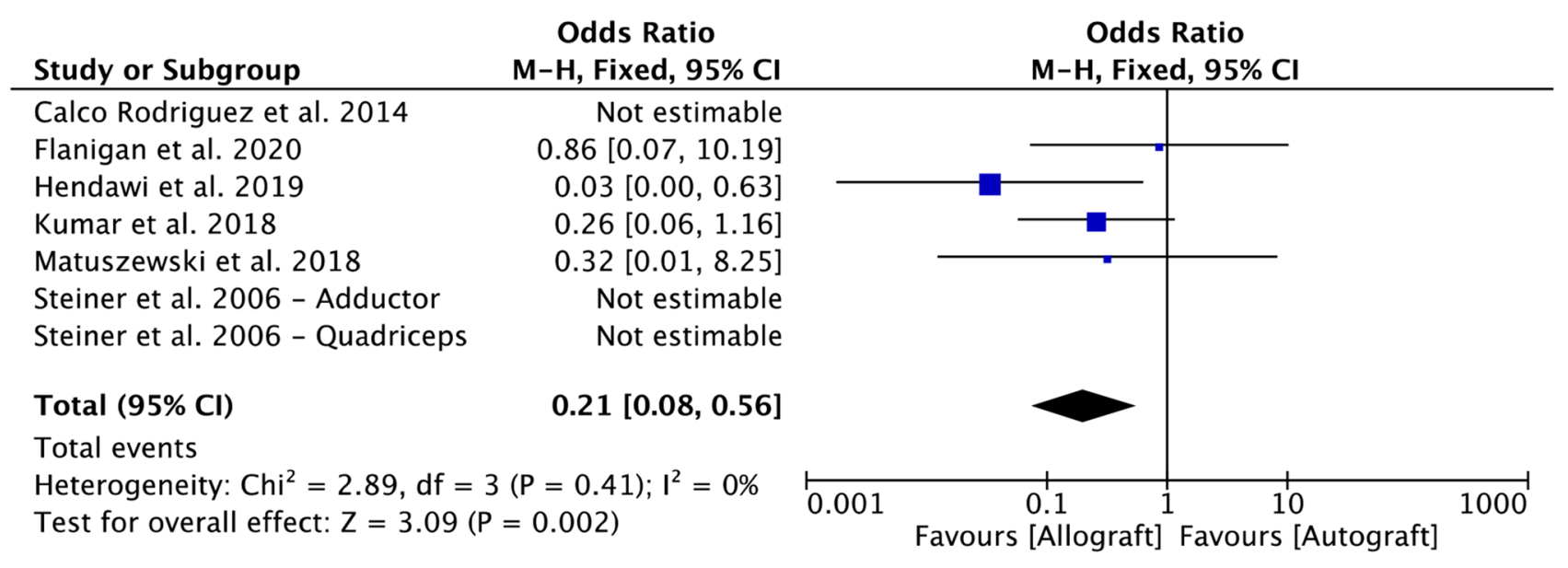

Fig. 4 Forest plot of the outcome: re-dislocation ( $C I$ confidence interval)

of the anatomical, physiological, and biomechanical differences between the two ligaments. Different from the MPFL, the ACL is an intraarticular structure. Intra- and extra-articular ligaments are subjected to different influences, stimulations, signaling, and vascular supply [6, 7]. Following injury, intra-articular ligaments exhibit reduced healing and higher failure rates compared to extra-articular ligaments. More specifically, when treated non-operatively, the ACL demonstrates a failure to heal rate of $90 \%$ [14]. This rate of failure is far higher than those observed in extra-articular ligaments, such as the MCL, when treated non-operatively [29]. Biomechanically, even though initially the strength of the repaired ligament is similar, over time the strength of intra-articular repaired ligaments decreases [14], while the strength of extra-articular ligament repairs increases [55].

This study has several limitations. One limitation is the small number of studies and consequently procedures available for review. Secondly, the retrospective nature of the included studies is another limitation of this work. The current literature lacks prospective analyses with blinding or sample randomization. Future studies should improve on these limitations, allowing higher-quality analyses. Additionally, inclusion and exclusion criteria of the studies included for analysis were heterogeneous. There was high variability among predisposing bone morphologies, risk factors, procedures, graft sources, follow-up, age, type of instability (recurrent, acute), and interventions (isolated, combined). This represents an important source of bias; however, considering the lack of data in the literature, no further subgroup analyses were possible. Moreover, the analyses were affected by a high level of heterogeneity; therefore, results from the present study must be interpreted with caution. Future investigations should overcome current shortcomings, performing studies with more homogeneous characteristics and indications, giving additional information concerning patient risk factors. Graft choice is complex, and to date, there is no universally agreed graft for MPFL reconstruction. Important considerations in graft choice include the ideal biomechanical proprieties (e.g., stiffness, viscoelasticity, tensile strength, thickness) of each graft. These remain undefined, and therefore no strong endorsement can be made. Future studies should also take advantage of more recently developed PROMs, such as the Banff Patella Instability Instrument (BPII) [19] and the Norwich Patellar Instability (NPI) [54] scores. These scores achieved high reliability for those patients with patellofemoral instability. Future 
studies with longer follow-up will be required to investigate possible attenuation of the MPFL allograft strength over time.

\section{Conclusion}

Allografts may represent a feasible alternative to traditional autograft for MPFL reconstruction in selected patients with patellofemoral instability. Allograft tendons yielded similar PROMs, rates of persistent instability, and revision compared to autograft tendons. Patients in whom an MPFL reconstruction had been performed using allografts evidenced lower re-dislocation rate than those in whom autografts had been used.

Funding Open access funding provided by Università degli Studi di Salerno within the CRUI-CARE Agreement. No external source of funding was used.

\section{Declarations}

Conflict of interest The authors declare that they have no conflicts of interest.

Ethical approval This article does not contain any studies with human participants or animals performed by any of the authors.

Informed consent For this type of study informed consent is not required.

Open Access This article is licensed under a Creative Commons Attribution 4.0 International License, which permits use, sharing, adaptation, distribution and reproduction in any medium or format, as long as you give appropriate credit to the original author(s) and the source, provide a link to the Creative Commons licence, and indicate if changes were made. The images or other third party material in this article are included in the article's Creative Commons licence, unless indicated otherwise in a credit line to the material. If material is not included in the article's Creative Commons licence and your intended use is not permitted by statutory regulation or exceeds the permitted use, you will need to obtain permission directly from the copyright holder. To view a copy of this licence, visit http://creativecommons.org/licenses/by/4.0/.

\section{References}

1. Agarwalla A, Liu JN, Garcia GH, Gowd AK, Puzzitiello RN, Yanke AB et al (2020) Return to sport following isolated lateral opening wedge distal femoral osteotomy. Cartilage. https://doi. org/10.1177/19476035209247751947603520924775

2. Aicale R, Oliva F, N M, (2020) Defensive antibacterial coating (DAC(B) for prevention of infection in ACL reconstruction: a feasibility study. Muscles Ligaments Tendons J 10:151-153

3. Aicale R, Maffulli N (2020) Combined medial patellofemoral and medial patellotibial reconstruction for patellar instability: a PRISMA systematic review. J Orthop Surg Res 15:529
4. Bartsch A, Lubberts B, Mumme M, Egloff C, Pagenstert G (2018) Does patella alta lead to worse clinical outcome in patients who undergo isolated medial patellofemoral ligament reconstruction? A systematic review. Arch Orthop Trauma Surg 138:1563-1573

5. Baumann CA, Pratte EL, Sherman SL, Arendt EA, Hinckel BB (2018) Reconstruction of the medial patellotibial ligament results in favorable clinical outcomes: a systematic review. Knee Surg Sports Traumatol Arthrosc 26:2920-2933

6. Bray RC, Leonard CA, Salo PT (2003) Correlation of healing capacity with vascular response in the anterior cruciate and medial collateral ligaments of the rabbit. J Orthop Res 21:1118-1123

7. Bray RC, Leonard CA, Salo PT (2002) Vascular physiology and long-term healing of partial ligament tears. J Orthop Res 20:984-989

8. Briggs KK, Lysholm J, Tegner Y, Rodkey WG, Kocher MS, Steadman JR (2009) The reliability, validity, and responsiveness of the Lysholm score and Tegner activity scale for anterior cruciate ligament injuries of the knee: 25 years later. Am J Sports Med 37:890-897

9. Calvo Rodriguez R, Figueroa Poblete D, Anastasiadis Le Roy Z, Etchegaray Bascur F, Vaisman Burucker A, Calvo Mena R (2015) Reconstruction of the medial patellofemoral ligament: evaluation of the clinical results of autografts versus allografts. Rev Esp Cir Ortop Traumatol 59:348-353

10. Carmont MR, Maffulli N (2007) Medial patellofemoral ligament reconstruction: a new technique. BMC Musculoskelet Disord 8:22

11. Coleman BD, Khan KM, Maffulli N, Cook JL, Wark JD (2000) Studies of surgical outcome after patellar tendinopathy: clinical significance of methodological deficiencies and guidelines for future studies. Victorian Institute of Sport Tendon Study Group. Scand J Med Sci Sports 10:2-11

12. Copay AG, Eyberg B, Chung AS, Zurcher KS, Chutkan N, Spangehl MJ (2018) Minimum clinically important difference: current trends in the orthopaedic literature, part II: lower extremity: a systematic review. JBJS Rev 6:e2

13. Dragoo JL, Nguyen M, Gatewood CT, Taunton JD, Young S (2017) Medial patellofemoral ligament repair versus reconstruction for recurrent patellar instability: two-year results of an algorithm-based approach. Orthop J Sports Med 5:2325967116689465

14. Feagin JA Jr, Curl WW (1976) Isolated tear of the anterior cruciate ligament: 5-year follow-up study. Am J Sports Med 4:95-100

15. Flanigan DC, Shemory S, Lundy N, Stitgen M, Long JM, Magnussen RA (2020) Medial patellofemoral ligament reconstruction with allograft versus autograft tissue results in similar recurrent dislocation risk and patient-reported outcomes. Knee Surg Sports Traumatol Arthrosc. https://doi.org/10.1007/s00167-020-05920-x

16. Gao G, Liu P, Xu Y (2020) Treatment of patellar dislocation with arthroscopic medial patellofemoral ligament reconstruction using gracilis tendon autograft and modified double-patellar tunnel technique: minimum 5-year patient-reported outcomes. J Orthop Surg Res 15:25

17. Greis PE, Koch BS, Adams B (2012) Tibialis anterior or posterior allograft anterior cruciate ligament reconstruction versus hamstring autograft reconstruction: an economic analysis in a hospital-based outpatient setting. Arthroscopy 28:1695-1701

18. Hendawi T, Godshaw B, Flowers C, Stephens I, Haber L, Waldron S (2019) Autograft vs allograft comparison in pediatric medial patellofemoral ligament reconstruction. Ochsner J 19:96-101

19. Hiemstra LA, Kerslake S, Lafave MR, Heard SM, Buchko GM, Mohtadi NG (2013) Initial validity and reliability of the Banff Patella instability instrument. Am J Sports Med 41:1629-1635

20. Hohn E, Pandya NK (2017) Does the utilization of allograft tissue in medial patellofemoral ligament reconstruction in pediatric and adolescent patients restore patellar stability? Clin Orthop Relat Res 475:1563-1569 
21. Howick JCI, Glasziou P, Greenhalgh T, Heneghan C, Liberati A, Moschetti I, Phillips B, Thornton H, Goddard O, Hodgkinson M (2011) The 2011 Oxford Levels of Evidence. Oxf Centre Evid Based Med. https://www.cebm.net/index.aspx?o=5653

22. Hu J, Qu J, Xu D, Zhou J, Lu H (2013) Allograft versus autograft for anterior cruciate ligament reconstruction: an up-to-date metaanalysis of prospective studies. Int Orthop 37:311-320

23. Jackson DW, Windler GE, Simon TM (1990) Intraarticular reaction associated with the use of freeze-dried, ethylene oxide-sterilized bone-patella tendon-bone allografts in the reconstruction of the anterior cruciate ligament. Am J Sports Med 18:1-10

24. Jones KJ, Kelley BV, Arshi A, McAllister DR, Fabricant PD (2019) Comparative effectiveness of cartilage repair with respect to the minimal clinically important difference. Am J Sports Med 47:3284-3293

25. Kan SL, Yuan ZF, Ning GZ, Yang B, Li HL, Sun JC et al (2016) Autograft versus allograft in anterior cruciate ligament reconstruction: a meta-analysis with trial sequential analysis. Medicine (Baltimore) 95:e4936

26. Kujala UM, Jaakkola LH, Koskinen SK, Taimela S, Hurme M, Nelimarkka O (1993) Scoring of patellofemoral disorders. Arthroscopy 9:159-163

27. Kumar N, Bastrom TP, Dennis MM, Pennock AT, Edmonds EW (2018) Adolescent medial patellofemoral ligament reconstruction: a comparison of the use of autograft versus allograft hamstring. Orthop J Sports Med 6:2325967118774272

28. Kyung HS, Kim HJ (2015) Medial patellofemoral ligament reconstruction: a comprehensive review. Knee Surg Relat Res 27:133-140

29. Larsen LB, Madsen JE, Hoiness PR, Ovre S (2004) Should insertion of intramedullary nails for tibial fractures be with or without reaming? A prospective, randomized study with 3.8 years' follow-up. J Orthop Trauma 18:144-149

30. Li J, Li Y, Wei J, Wang J, Gao S, Shen Y (2014) A simple technique for reconstruction of medial patellofemoral ligament with bone-fascia tunnel fixation at the medial margin of the patella: a 6-year-minimum follow-up study. J Orthop Surg Res 9:66

31. Maffulli N, Aicale R, D'Addona A, Young DA, Kader DF, Oliva F (2020) Combined medial patellofemoral and patellotibial reconstruction with soft tissue fixation in recurrent patellar dislocation. Injury 51:1867-1873

32. Marcheggiani Muccioli GM, Lullini G, Grassi A, Macchiarola L, Cammisa E, Maccaferri B et al (2020) Good results are reported at 60 -month follow-up after medial patello-femoral ligament reconstruction with fascia lata allograft for recurrent patellar dislocation. Knee Surg Sports Traumatol Arthrosc. https://doi.org/10.1007/s00167-020-06142-x

33. Marot V, Sanchis-Alfonso V, Perelli S, Gelber PE, Sanchez Rabago CJ, Ginovart G et al (2021) Isolated reconstruction of medial patellofemoral ligament with an elastic femoral fixation leads to excellent clinical results. Knee Surg Sports Traumatol Arthrosc 29:800-805

34. Matuszewski L, Ciszewski A, Wilczyński M, M C, (2017) Surgery technique of an anatomical MPFL reconstruction using allograft in children with recurrent patellar dislocation. Chir Narzadow Ruchu Ortop Pol 82:78-81

35. Matuszewski L, Trams M, Ciszewski A, Wilczynski M, Trams E, Jakubowski P et al (2018) Medial patellofemoral ligament reconstruction in children: a comparative randomized shortterm study of fascia lata allograft and gracilis tendon autograft reconstruction. Medicine (Baltimore) 97:e13605

36. McNeilan RJ, Everhart JS, Mescher PK, Abouljoud M, Magnussen RA, Flanigan DC (2018) Graft choice in isolated medial patellofemoral ligament reconstruction: a systematic review with meta-analysis of rates of recurrent instability and patient-reported outcomes for autograft, allograft, and synthetic options. Arthroscopy 34:1340-1354

37. Migliorini F, Baroncini A, Eschweiler J, Tingart M, Maffulli N (2020) Interference screws vs suture anchors for isolated medial patellofemoral ligament femoral fixation: a systematic review. $\mathrm{J}$ Sport Health Sci. https://doi.org/10.1016/j.jshs.2020.11.011

38. Migliorini F, Driessen A, Quack V, Gatz M, Tingart M, Eschweiler J (2020) Surgical versus conservative treatment for first patellofemoral dislocations: a meta-analysis of clinical trials. Eur J Orthop Surg Traumatol. https://doi.org/10.1007/ s00590-020-02638-X

39. Migliorini F, Driessen A, Quack V, Schenker H, Tingart M, Eschweiler J (2020) Patellar fixation graft via suture anchors versus tunnel techniques during isolated MPFL reconstruction for recurrent patellofemoral instability: a systematic review of the literature. Arch Orthop Trauma Surg. https://doi.org/10. 1007/s00402-020-03420-8

40. Migliorini F, Rath B, Tingart M, Meisen N, Eschweiler J (2019) Surgical management for recurrent patellar dislocations in skeletally immature patients. Eur J Orthop Surg Traumatol 29:1815-1822

41. Migliorini F, Trivellas A, Driessen A, Quack V, Tingart M, Eschweiler J (2020) Graft choice for isolated MPFL reconstruction: gracilis versus semitendinosus. Eur J Orthop Surg Traumatol. https://doi.org/10.1007/s00590-020-02636-z

42. Migliorini F, Trivellas A, Eschweiler J, Betsch M, Tingart M, Maffulli N (2021) Pedicled strip of quadriceps tendon graft for primary medial patellofemoral ligament reconstruction in recurrent patellofemoral instability: a systematic review. Arthroscopy. https://doi.org/10.1016/j.arthro.2021.01.048

43. Mistry H, Metcalfe A, Colquitt J, Loveman E, Smith NA, Royle P et al (2019) Autograft or allograft for reconstruction of anterior cruciate ligament: a health economics perspective. Knee Surg Sports Traumatol Arthrosc 27:1782-1790

44. Moher D, Liberati A, Tetzlaff J, Altman DG, Group P (2009) Preferred reporting items for systematic reviews and meta-analyses: the PRISMA statement. BMJ 339:b2535

45. Nha KW, Bae JH, Hwang SC, Nam YJ, Shin MJ, Bhandare NN et al (2019) Medial patellofemoral ligament reconstruction using an autograft or allograft for patellar dislocation: a systematic review. Knee Surg Relat Res 31:8

46. Nikku R, Nietosvaara Y, Aalto K, Kallio PE (2005) Operative treatment of primary patellar dislocation does not improve medium-term outcome: a 7-year follow-up report and risk analysis of 127 randomized patients. Acta Orthop 76:699-704

47. Petri M, Ettinger M, Stuebig T, Brand S, Krettek C, Jagodzinski $\mathrm{M}$ et al (2015) Current concepts for patellar dislocation. Arch Trauma Res 4:e29301

48. Prodromos C, Joyce B, Shi K (2007) A meta-analysis of stability of autografts compared to allografts after anterior cruciate ligament reconstruction. Knee Surg Sports Traumatol Arthrosc $15: 851-856$

49. Rappe M, Horodyski M, Meister K, Indelicato PA (2007) Nonirradiated versus irradiated Achilles allograft: in vivo failure comparison. Am J Sports Med 35:1653-1658

50. Ren B, Zhang X, Zhang L, Zhang M, Liu Y, Tian B et al (2019) Isolated trochleoplasty for recurrent patellar dislocation has lower outcome and higher residual instability compared with combined MPFL and trochleoplasty: a systematic review. Arch Orthop Trauma Surg 139:1617-1624

51. Roberts TS, Drez D Jr, McCarthy W, Paine R (1991) Anterior cruciate ligament reconstruction using freeze-dried, ethylene oxidesterilized, bone-patellar tendon-bone allografts. Two year results in thirty-six patients. Am J Sports Med 19:35-41

52. Shamrock AG, Day MA, Duchman KR, Glass N, Westermann RW (2019) Medial patellofemoral ligament reconstruction in skeletally 
immature patients: a systematic review and meta-analysis. Orthop J Sports Med 7:2325967119855023

53. Slenker NR, Tucker BS, Pepe MD, Marchetto PA, Cohen SB (2013) Short-/intermediate-term outcomes after medial patellofemoral ligament reconstruction in the treatment of chronic lateral patellofemoral instability. Phys Sportsmed 41:26-33

54. Smith TO, Donell ST, Clark A, Chester R, Cross J, Kader DF et al (2014) The development, validation and internal consistency of the Norwich Patellar Instability (NPI) score. Knee Surg Sports Traumatol Arthrosc 22:324-335

55. Spindler KP, Dawson JM, Stahlman GC, Davidson JM, Nanney LB (2002) Collagen expression and biomechanical response to human recombinant transforming growth factor beta (rhTGFbeta2) in the healing rabbit MCL. J Orthop Res 20:318-324

56. Steiner TM, Torga-Spak R, Teitge RA (2006) Medial patellofemoral ligament reconstruction in patients with lateral patellar instability and trochlear dysplasia. Am J Sports Med 34:1254-1261

57. Sun K, Tian S, Zhang J, Xia C, Zhang C, Yu T (2009) Anterior cruciate ligament reconstruction with BPTB autograft, irradiated versus non-irradiated allograft: a prospective randomized clinical study. Knee Surg Sports Traumatol Arthrosc 17:464-474
58. Tegner Y, Lysholm J (1985) Rating systems in the evaluation of knee ligament injuries. Clin Orthop Relat Res 198:43-49

59. Weinberger JM, Fabricant PD, Taylor SA, Mei JY, Jones KJ (2017) Influence of graft source and configuration on revision rate and patient-reported outcomes after MPFL reconstruction: a systematic review and meta-analysis. Knee Surg Sports Traumatol Arthrosc 25:2511-2519

60. Zeng C, Gao SG, Li H, Yang T, Luo W, Li YS et al (2016) Autograft versus allograft in anterior cruciate ligament reconstruction: a meta-analysis of randomized controlled trials and systematic review of overlapping systematic reviews. Arthroscopy 32(153-163):e118

Publisher's Note Springer Nature remains neutral with regard to jurisdictional claims in published maps and institutional affiliations. 